\section{SCIENCE AS A HUMANITY}

\author{
By Prof. W. G. DE BURGH, F.B.A.
}

$\mathrm{T}$ "HE session on "Science as a Humanity" held during the recent British Association Conference on "Science and the Citizen" is of good augury, for it is a further testimony to the fact, evident of late in many quarters, that the old rivalry of science and the humanities is a back number, and is rapidly ceasing to cast a cloud over the future of our national education. There has always been something unnatural about the controversy; for, as Prof. J. L. Myres reminds us in his opening address as well as Dr. Waddington at the close, both the parties share a common parentage in the epoch of the Renaissance, inheriting therefrom an identity of aim and interest that is belied by their artificial severance. We can picture how Copernicus, Kepler and even Harvey would have recoiled from the suggestion that the study of classical antiquity was irrelevant, not to say inimical, to that of the sciences of Nature. If later generations have emphasized the contrast, to the detriment both of science and the humanities, the responsibility lies chiefly with a philosopher, Immanuel Kant. For Kant, science meant Newtonian physics; man's moral personality and the entire realm of ethical and religious value were excluded from the knowledge of speculative reason and regarded as objects of practical faith. No wonder that such limitation of the scope of science provoked a protest, of which Wilhelm Dilthey was the leading champion in Germany, to the effect that over and above the sciences of Nature were the sciences of spirit (Geisteswissenschaften) which were none the less deserving of the name of sciences, though their objects and methods were poles asunder from those of mathematical physics.

Science is an ambiguous term and both Prof. Myres and Dr. Waddington see the necessity of clearly understanding what we mean by it. Kant's use is far too narrow, for it would scarcely include biology, to say nothing of psychology or anthropology. On the other hand, to take it as the equivalent of the German Wissenschaft is far too wide; if every inquiry that employs an elaborate technique is a science, then not only are history and archæology sciences, but also all the departmental researches of the pundits of the British Museum, and the higher criticism of the Old and New Testament, deserve that title ; and what branch of knowledge is then left over for the humanities? Dr. Waddington, though he endorses Prof. Myres's inclusion both of the "interactions of individuals, which are incommensurable qualitatively, and of value" within the scope of science, dissents from the view, sometimes put forward by scientific advocates of the wider interpretation, that science can be stretched to cover "all the achievements of logical or rational thought". Science, for him as for Prof. Myres, is the product of the wedlock of reason and experiment, and the empirical, if not always the experimental, factor is an essential constituent of its meaning. That, he claims justly, is the hall-mark of Greek culture," "a culture of quick-witted, subtle Individualists interested on the one hand in deep speculative generalisations, and on the other in highly practical matters of an empirical nature". What is distinctive of the humanities, he tells us, is that they are grounded on "feeling applied to the individual". This definition may be accepted, provided always that the term "feeling" is not taken to exclude the possibility of a knowledge of the individual such as is achieved through history, through literature and the arts, and through personal relationships between man and man and possibly--though this is a larger question-between man and God, a knowledge which is none the less rational in that it is closely integrated with emotional and volitional activity. That this personal knowledge can function even within the strictly scientific fold, for the untold enrichment of the conceptual thinking that properly characterizes science, will scarcely be disputed by those who appreciate the intimate contacts with birds and other animals enjoyed by such lovers of Nature as W. $\mathrm{H}$. Hudson or the late Lord Grey of Fallodon. A wide field for reflection is here thrown open, very relevant to the topic of the cultural value of science, by the co-operation of the personal and impersonal methods of inquiry.

Among those who took part in this conference, Dr. R. V. Southwell is the one who seems to appreciate this most clearly. He points out that what is requisite for the training of the citizen's personality cannot be restricted to the technique of the laboratory, or even to "acquaintance with scientific thought". This indeed is necessary, but it is not sufficient. Science calls for supplementation by the humanities. "No less needed", he says in a highly instructive passage, "is the thinking that reveals itself as wisdom in the affairs of life itself. The humanists claim that it is developed by their studies, and I think I have noticed in many of them a suppleness (if the word will serve) which men of science too often lack. Here then is a case for 'the humanities' in a balanced education, and in my belief they are an essential part: though I am by no means satisfied with the way in which they are studied under our examina. tion system, and can perceive, I think, the danger of a teaching so completely based upon authority. Too often, dislike of the premature conclusion leads to a shunning of decisions in a world where decisions are imperative: But what is still wanting, science, I believe, can give; realization that hard problems require hard thinking, and that the effort must be made." This is excellently said, and carries a lesson both for the scientist and the humanist. It may be that Dr. Southwell exaggerates the deference to authority in current humanistic teaching, and glozes with natural partiality over the excessive conservatism that has often prejudiced original advance in science. But the ready response that his eirenicon will evoke in humanist quarters may be gauged by a reference to the Provost of Kings' presidential address at the recent meeting of the Classical Association at Cambridge. He will have none of the familiar party slogans: "I am for the Classics", "I am for Religion", "I am for Science", and appeals to the temper of Erasmus, typical of the great days of Humanism, and still prevalent in English education in the seventeenth century. "Would Harvey of Caius," he asks, "who discovered the circulation of the blood, have done better in his science if he had been sent to an expensive, well-taught, well-laboratoried secondary school and had sat at school for his M.B. ?"

Of course, there are difficulties in the way of realizing the union of the scientific spirit with that of humanism in a concrete educational programme. Are arts subjects to be added to science courses, and science subjects to courses in arts? Or is science to be taught culturally so as itself to be a humanity in its own right? Both lines of approach should 
be tried, after the true scientific method, experimentally. Only the other day, the late Prof. Muirhead, then the doyen among English philosophers, publishing his reminiscences as an octogenarian, recalled the arts curriculum at Glasgow in the seventies of last century, which still kept alive its fidelity to the medieval tradition. He gives as his reasoned opinion, formed after experience of the Oxford system and that of the new English universities and of several of the great American universities, both State and other, that, "for breadth of training and as a preparation either for business life, for the professions, or for further specialized study, there is nothing which, on the whole, has proved better than this old Quadrivium of Classics, Mathematies, Philosophy and Physics, all softened and humanized by a halo of English literature". Then there is the further problem of finding teachers of science able and willing to bring home its cultural significance to students without experience of a laboratory. The tradition that the training of highly specialized researchers alone is the concern of the teacher of science is so strongly rooted that the cultural value of science has almost vanished from the picture. The arts student in our universities has no opportunity of learning the bearings on human life of the mysteries that are being enacted within the precincts of the laboratory. There is serious need for lecturers to mediate between the specialist and the public, possessed of the gift for expounding, like Huxley in his generation, or Bertrand Russell, in his "A.B.C. of Atoms", the leading currents of contemporary scientific thought in language intelligible to the thinking public.

All the speakers at this Conference, except perhaps Prof. Le Gros Clark, who confines his remarks to the teaching of biology and its applications to the education of the citizen, recognize that it is the task of science to throw light on the problem of moral value. Dr. Waddington, as we should expect from his recent volume on "Science and Ethics", which has deservedly arrested the interest of the public, believes that evolutionary science offers the key to its solution. That "man himself is, after all, a member of the animal world" is, of course, a truism of which we do not need the biologist to assure us ; it was well known to antiquity, and there is a mass of contemporary evidence to bring home to us how close the ape and the tiger lie to the surface of human nature. But man is not merely an animal; he is a thinking animal, an animal with a moral consciousness, capable of extending his outlook both in thought and action beyond the bourne of time and space.

In my contribution to Dr. Waddington's book, I ventured to question whether the appeal to evolution could justify the absolute claim of moral obligation. Dr. Waddington's suggestion, reiterated at this Conference, that "the highest duty of man should be to carry forward the main stream of evolution" seems to make larger drafts upon the future than is warranted by our knowledge of the course of evolution. Does that knowledge really bear out Prof. Myres's contention that, despite the tragic antithesis of the ethical and cosmic processes, "good must win" ? Prof. Myres adds the proviso, "if all good men work together in the cause of good". Can evolutionary science enlighten us, as Dr. Waddington believes it can, as to the nature of what is good? The menace of entropy is surely enough to give us pause. Even if we restrict our view to the facts of recorded history, what evidence do we find of uniform advance in human morals? Does it not look to-day as if the human race were moving rapidly and of deliberate purpose down the slope that léads to selfdestruction?

Dr. Waddington closes his address with some pertinent remarks on the trend towards socialism, characteristic of the modern cultural outlook, and suggests that science, by emphasizing man's essentially social nature, may play a "by no means negligible part in bringing the new society to birth". He holds that as in the humanism of the Renaissance, a purely this-worldly individualism, which found appropriate embodiment in art, superseded the other-worldly sociality of the Middle Ages; so a this-worldly sociality is destined to replace the individualism of the capitalist epoch that is now in process of disintegration, with science as its fitting medium of expression. Science will thus replace art, as art replaced religion, as the predominant human interest.

But is this picture of the dialectical process true to fact? Has interest in art shown any tendency to decline, for example, in Soviet Russia? And what about religion? "En mon temps on avait Dieu", said the old French marquis in the play; and it sometimes looks as though even in Russia they had him still. It is at all events matter for argument whether theism cannot offer a more promising solution of the problem of value than the optimism which pins its faith to the evolutionary process. But this is a view which, I fear, would scarcely find favour among those who collaborated in this Conference.

\section{OBITUARIES}

\section{Dr. Henry Forster Morley}

THE death of Henry Forster Morley occurred on April 3, 1943, in his eighty-eighth year. He was well known to chemists and other scientific men, both in Great Britain and abroad. Over a long period of time Morley and his wife, who died only a few weeks before him, were frequent visitors at scientific gatherings and until recently they customarily attended the conversaziones and evening meetings of the Royal Institution.

Forster Morley, born on October 23, 1855, was the eldest son of the late Prof. Henry Morley, sometime professor of English literature at University College, London. He was educated at University College School, University College, London, and proceeded to the Universities of Paris, Berlin and Bonn. $\mathrm{He}$ was assistant professor of chemistry at University College, London, in the time of Williamson's professorship. He also held the posts of professor of chemistry at Queen's College, London, and lecturer' in chemistry at Charing Cross Hospital. He acted as examiner in chemistry to the Universities of London, Oxford, to the Conjoint Board, the Society of Apothecaries and elsewhere.

In addition to his original publications in chemistry, Forster Morley prepared, in 1899, in conjunction with Patterson Muir, a revised edition of "Watt's Dictionary of Chemistry", a work which still continues to serve useful purposes. The text-book of organic chemistry he published in 1884 has lasting merit, inasmuch as in dealing with the practical relationship, properties and preparation of organic 